\title{
Platelet-derived extracellular vesicles promote the migration and invasion of rheumatoid arthritis fibroblast-like synoviocytes via CXCR2 signaling
}

\author{
WENWEN WANG ${ }^{1,2^{*}}$, ZIJING DENG ${ }^{1 *}$, GUIPING LIU $^{3 *}$, JIE YANG $^{1}$, WEI ZHOU ${ }^{4}$, \\ CHEN ZHANG ${ }^{1}$, WEIGAN SHEN ${ }^{1,5,6}$ and YU ZHANG ${ }^{1,5,6}$
}

\begin{abstract}
${ }^{1}$ Department of Cell Biology, School of Medicine of Yangzhou University, Yangzhou, Jiangsu 225000;
${ }^{2}$ Department of Rheumatology, Nantong City No. 1 People's Hospital and Second Affiliated Hospital of Nantong University, Nantong, Jiangsu 226000; ${ }^{3}$ Department of Rheumatology, Taizhou People's Hospital, Taizhou, Jiangsu 225300; ${ }^{4}$ Department of Internal Medicine, Affiliated Hospital of Yangzhou University;

5 Jiangsu Co-Innovation Center for Prevention and Control of Important Animal Infectious Diseases and Zoonoses; ${ }^{6}$ Jiangsu Key Laboratory of Integrated Traditional Chinese and Western Medicine for Prevention and Treatment of Senile Diseases, Yangzhou University, Yangzhou, Jiangsu 225000, P.R. China
\end{abstract}

Received January 17, 2021; Accepted July 9, 2021

DOI: $10.3892 /$ etm.2021.10554

\begin{abstract}
Platelet-derived extracellular vesicles (PEVs), which are generated from the plasma membrane during platelet activation, may be involved in the inflammatory processes of rheumatoid arthritis (RA). The motility of RA fibroblast-like synoviocytes (RA-FLS) plays a key role in the development of synovial inflammation and joint erosion. However, the effects of PEVs on the motility of RA-FLS remain unclear. Thus, the present study aimed to investigate the active contents and potential molecular mechanisms underlying the role of PEVs in regulating the migration and invasion of RA-FLS. The results demonstrated that PEVs contain certain chemokines associated with cell migration and invasion, including $\mathrm{C}-\mathrm{C}$ motif chemokine ligand 5, C-X-C motif chemokine ligand (CXCL)4 and CXCL7. Furthermore, SB225002, an antagonist of C-X-C motif chemokine receptor 2 (CXCR2; a CXCL7 receptor), partially prevented the migration and invasion of RA-FLS induced by PEVs, suggesting that PEVs may activate a CXCR2-mediated signaling pathway in RA-FLS. In addition,
\end{abstract}

Correspondence to: Professor Yu Zhang or Professor Weigan Shen, Department of Cell Biology, School of Medicine of Yangzhou University, 136 Jiangyang Middle Road, Yangzhou, Jiangsu 225000, P.R. China

E-mail: yzzy10182001@aliyun.com

E-mail: shenweigan@hotmail.com

${ }^{*}$ Contributed equally

Key words: platelet-derived extracellular vesicles, rheumatoid arthritis fibroblast-like synoviocytes, C-X-C motif chemokine receptor 2, cell migration, cell invasion
SB225002 antagonized the phosphorylation of $\mathrm{I} \kappa \mathrm{B}$ and NF- $\kappa \mathrm{B}$ in RA-FLS induced by PEVs. Taken together, the results of the present study suggested that PEVs may promote the migration and invasion of RA-FLS by activating the NF- $\kappa$ B pathway mediated by the CXCR2 signaling pathway.

\section{Introduction}

Rheumatoid arthritis (RA) is a systemic autoimmune disease that mainly causes chronic inflammation in synovial tissues $(1,2)$. Accumulating evidence suggests that fibroblast-like synoviocytes (FLS) play a critical role in the pathogenesis of RA, particularly in the erosion of cartilage and bone $(3,4)$. Stable activated RA-FLS exhibit tumor cell-like phenotypes, such as overproduction of inflammatory cytokines, excessive proliferation, aggressive migration and invasion $(5,6)$. Therefore, regulating the migration and invasion of RA-FLS may be useful for ameliorating joint destruction in RA.

Platelet-derived extracellular vesicles (PEVs) are heterogeneous vesicles, sized $0.1-1.0 \mu \mathrm{m}$, that are released from platelet membranes and have been attracting substantial attention (7). PEVs may play a role in several pathological conditions, such as ischemic stroke, cardiovascular diseases, cancer and inflammatory diseases (8-10). It has been reported that the level of circulating PEVs is significantly elevated in various autoimmune diseases, such as RA, Sjogren's syndrome, systemic lupus erythematosus and antiphospholipid syndrome (11-13). Notably, the numbers of PEVs are increased in both the peripheral blood and joint cavity of patients with RA, and they are associated with disease activity, indicating that PEVs are closely associated with the occurrence and development of RA $(14,15)$. Increasing evidence suggest that PEVs not only deliver several bioactive molecules, including chemokines, enzymes and inflammatory mediators, but also induce 
monocytes and endothelial cells to release more inflammatory mediators to aggravate inflammatory processes (16-18). In addition, PEVs promote the proliferation, angiogenesis and migration and invasion of tumor cells by increasing the expression of MMPs (19-21). However, the role of PEVs in the pathogenesis of RA remains unclear.

Our previous study demonstrated that PEVs promote the migration and invasion of RA-FLS (22). The present study investigated the specific protein composition of PEVs by proteomics analysis and examined the chemokine contents of PEVs, such as C-C motif chemokine ligand 5 (CCL5), C-X-C motif chemokine ligand (CXCL) 4 and CXCL7. In addition, it was investigated whether SB225002, an antagonist of C-X-C motif chemokine receptor 2 (CXCR2; a CXCL7 receptor), could inhibit the migration and invasion of RA-FLS induced by PEVs, and whether these effects are mediated via suppression of I $\kappa \mathrm{B}$ and NF- $\kappa \mathrm{B}$ phosphorylation (23). The aim was to determine whether SB225002 can inhibit the motility of RA-FLS induced by PEVs, which may be a potential therapeutic target for RA.

\section{Materials and methods}

Cell culture. Human RA-FLS were purchased from Jennio Biotech Co., Ltd. and maintained in DMEM (Gibco; Thermo Fisher Scientific, Inc.) supplemented with 15\% FBS (HyClone; Cytiva), $100 \mathrm{U} / \mathrm{ml}$ penicillin and $100 \mu \mathrm{g} / \mathrm{ml}$ streptomycin (Invitrogen; Thermo Fisher Scientific, Inc.), at $37^{\circ} \mathrm{C}$ with $5 \%$ $\mathrm{CO}_{2}$. Primary RA-FLS from passages 3-6 were used in our experiments.

PEVs preparation and component analysis. Platelet-rich plasma (PRP), purchased from Red Cross Blood Station (Yangzhou, China), was centrifuged at $1,000 \mathrm{x}$ g for $5 \mathrm{~min}$ at room temperature. Washed platelets were prepared from PRP and resuspended in modified Tyrode's buffer (HyClone; Cytiva). PEVs were subsequently harvested by stimulating the platelets in washing buffer $\left(1 \mathrm{mM} \mathrm{CaCl}_{2}, 2 \mathrm{mM} \mathrm{MgCl}_{2}\right.$ and $10 \mu \mathrm{M}$ ADP) for $30 \mathrm{~min}$ at $37^{\circ} \mathrm{C}$ with gentle agitation, removing platelet aggregates at $3,000 \mathrm{x}$ g for $30 \mathrm{~min}$, followed by centrifugation at $15,000 \mathrm{x}$ g for $1 \mathrm{~h}$ at $4^{\circ} \mathrm{C}$. Subsequent verification of PEVs was assessed using PE-labeled anti-CD41 via flow cytometric analysis (FACS CantoII; Becton, Dickinson and Company), and the relative PEVs concentration was quantified using the BCA method. Subsequently, liquid chromatography with tandem mass spectrometry (LC-MS-MS) detection and component analysis were performed by Shanghai Applied Protein Technology Co., Ltd.

Bioinformatics. Gene Ontology (GO) and Kyoto Encyclopedia of Genes and Genomes (KEGG) analysis were performed using the David 6.8 online tool (http://david.ncifcrf.gov/). GO analysis was constituted with three domains: Biological process, cellular component and molecular function. KEGG analysis was performed to explore the signaling pathways of the differentially expressed proteins.

Immunofluorescence staining. RA-FLS were cultured in complete DMEM supplemented with $15 \%$ FBS with or without $50 \mu \mathrm{g} / \mathrm{ml} \mathrm{PEVs}$ for $24 \mathrm{~h}$, fixed with $4 \%$ paraformaldehyde for $15 \mathrm{~min}$ at room temperature and permeabilized with $0.5 \%$ Triton $\mathrm{X}-100$ for $15 \mathrm{~min}$ at room temperature. The actin cytoskeleton was visualized following incubation with rhodamine-conjugated phalloidin (Sigma-Aldrich; Merck $\mathrm{KGaA}$ ) for $2 \mathrm{~h}$ in the dark. Nuclei were counterstained with DAPI (Beyotime Institute of Biotechnology) for $10 \mathrm{~min}$ at $37^{\circ} \mathrm{C}$. Following thorough washing with PBS, coverslips were mounted on glass slides and micrographs were captured under a fluorescence microscope (magnification, x100).

Cell viability assay. RA-FLS were seeded into 96-well plates at a density of $5 \times 10^{3}$ cells/well for $24 \mathrm{~h}$ and subsequently treated with different concentrations of several chemokine receptor antagonists: BX471 (50, 100 and $150 \mathrm{nM}$; CCR1 antagonist, Sigma-Aldrich; Merck KGaA), AMG487 (0.5, 1 and $2 \mu \mathrm{M}$; CXCR3 antagonist, Sigma-Aldrich; Merck KGaA) and SB225002 (0.1, 0.2 and $0.4 \mu \mathrm{M}$; CXCR2 antagonist, Sigma-Aldrich; Merck KGaA). Following incubation for $24 \mathrm{~h}$ at $37^{\circ} \mathrm{C}, 10 \mu \mathrm{l}$ Cell Counting Kit-8 (CCK-8; Absin Bioscience, Inc.) reagent was added to each well and the optical density was measured at a wavelength of $450 \mathrm{~nm}$.

Wound healing assay. RA-FLS were seeded into 6-well plates at a density of $1 \times 10^{5}$ cells/well for $12 \mathrm{~h}$. Following incubation with serum-free DMEM for $12 \mathrm{~h}$ at $37^{\circ} \mathrm{C}$, linear scratches in the cell monolayer were generated using a $200-\mu 1$ pipette tip when cell confluence reached about $80-90 \%$. Subsequently, RA-FLS were cultured in serum-free DMEM supplemented with different concentration of PEVs $(0$ and $50 \mu \mathrm{g} / \mathrm{ml})$ and chemokine receptor antagonists for $24 \mathrm{~h}$. Images were captured under an inverted microscope (magnification, x100; Eclipse Ti; Nikon Corporation).

Transwell migration and invasion assay. Transwell chambers were used to assess cell migration and invasion. For the Transwell migration assay, $2 \times 10^{4}$ cells were plated in the upper chambers of Transwell plates (pore size, $8.0 \mu \mathrm{m}$; Corning, Inc.) in serum-free DMEM for $12 \mathrm{~h}$, followed by incubation with different concentrations of PEVs (0 and $50 \mu \mathrm{g} / \mathrm{ml})$ for $24 \mathrm{~h}$. The lower chamber was supplemented with DMEM containing $15 \%$ FBS as chemoattractant with corresponding PEVs and chemokine receptor antagonists. The inserts were removed after $24 \mathrm{~h}$ and the non-migratory cells were gently wiped off with a cotton swab. After fixation with $100 \%$ methanol for $2 \mathrm{~min}$, the migrated cells were stained with $10 \%$ Giemsa solution (Vazyme Biotech Co., Ltd.) for $15 \mathrm{~min}$ at room temperature and counted in eight randomly selected fields using an inverted microscope (magnification, x100; Eclipse Ti; Nikon Corporation). For the invasion assay, the inserts were precoated with $100 \mu \mathrm{l}$ Matrigel $(100 \mu \mathrm{g} / \mathrm{ml}$; BD Biosciences) $24 \mathrm{~h}$ prior to the experiment and the basement membranes were hydrated for $1 \mathrm{~h}$ at $37^{\circ} \mathrm{C}$.

Western blotting. Total protein was extracted from RA-FLS using the protein extraction kit (Vazyme Biotech Co., Ltd.) and protein concentration was quantified using the BCA assay method. Proteins were separated via 10\% SDS-PAGE, transferred onto PVDF membranes (MilliporeSigma) and blocked with $5 \%$ non-fat milk in $0.05 \%$ TBS-Tween-20 for $1 \mathrm{~h}$ at room temperature. The membranes were incubated with 
A

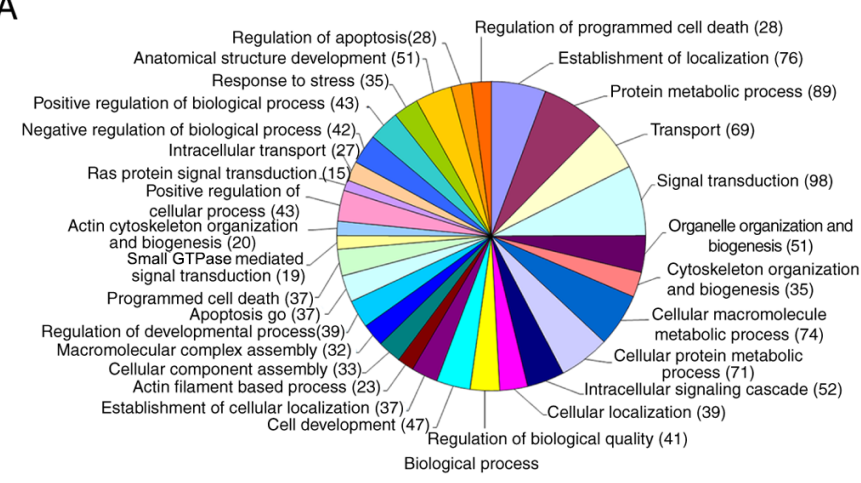

B

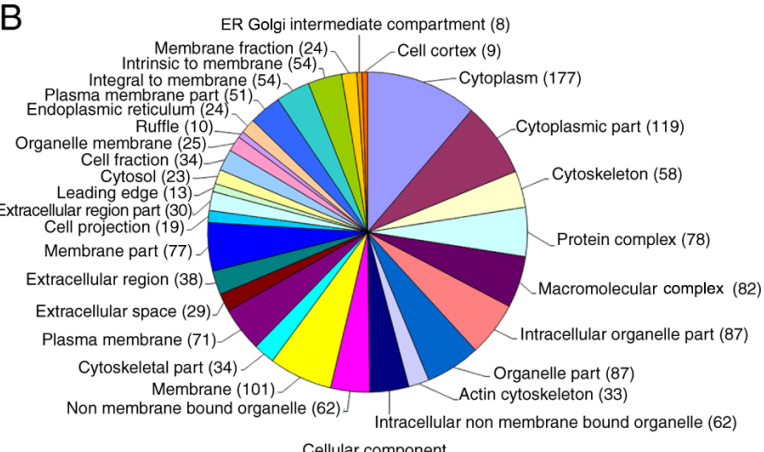

Cellular component

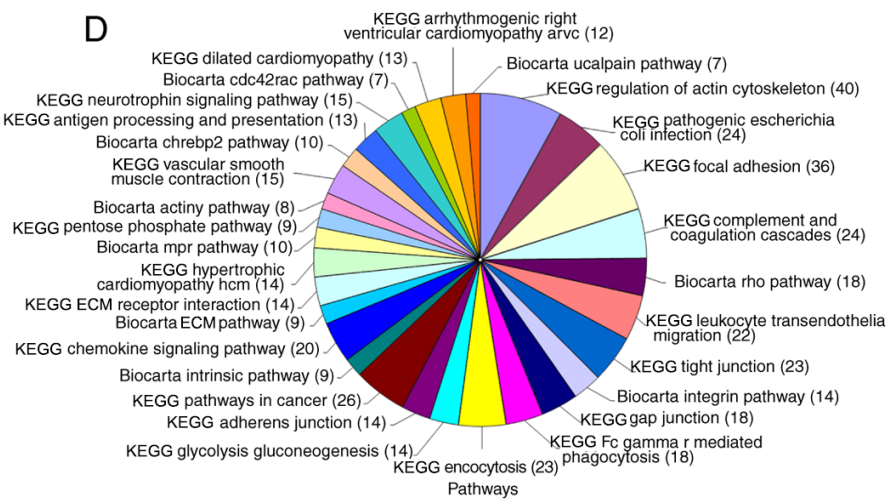

C Oxidoreductase activity (19) AP binding (5)

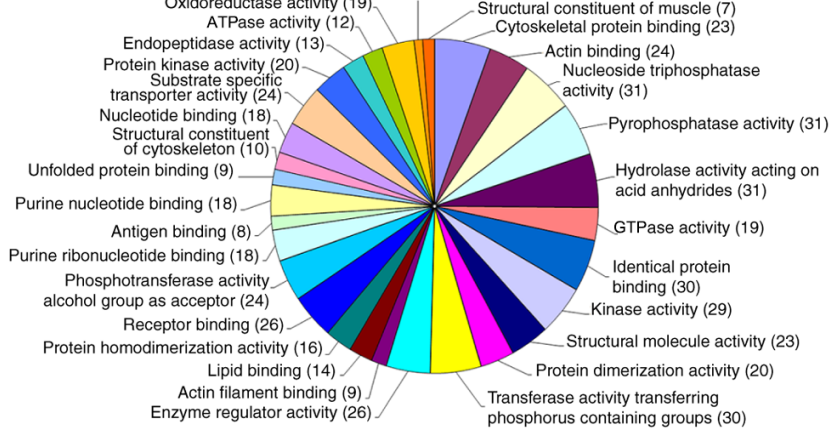

Molecular function

Figure 1. Gene Ontology and Kyoto Encyclopedia of Genes and Genomes analyses. Pie charts depicting the 5,256 proteins identified in the present study distributed into the following categories: (A) Biological process, (B) cellular component, (C) molecular function and (D) pathways.

primary antibodies against IкB (1:1,000; cat. no. 4812; Cell Signaling Technology, Inc.), phosphorylated (p)-IкB (1:1,000; cat. no. 2859; Cell Signaling Technology, Inc.), NF-кB (1:1,000; cat. no. 8242; Cell Signaling Technology, Inc.), p-NF- $\kappa B$ (1:1,000; cat. no. 3033; Cell Signaling Technology, Inc.) and GAPDH (1:1,000; cat. no. 2118; Cell Signaling Technology, Inc.) overnight at $4^{\circ} \mathrm{C}$. Following the primary antibody incubation, the membranes were incubated with the HRP-conjugated goat anti-rabbit polyclonal IgG secondary antibody $(1: 2,000$; cat. no. 7074; Cell Signaling Technology, Inc.). Protein bands were visualized by Pierce ECL Plus Western Blotting substrate (Thermo Fisher Scientific, Inc.) and subsequently analyzed using ImageJ software (version 1.51j8; National Institutes of Health). GAPDH was used as the internal control.

Statistical analysis. Statistical analysis was performed using SPSS 20.0 software (IBM Corp.). All experiments were performed in triplicate and data are presented as the mean \pm SD. The two-tailed paired Student's t-test was used to compare the differences between two groups. $\mathrm{P}<0.05$ was considered to indicate a statistically significant difference.

\section{Results}

Identification of chemokines in PEVs. LC-MS-MS demonstrated that there were 5,256 proteins in PEVs, and only proteins with $>4$ distinct peptides and $>20 \%$ coverage were considered as significant $(24,25)$. GO enrichment analysis with respect to these proteins in PEVs was performed to determine the biological process, cellular component and molecular function. KEGG pathway annotation demonstrated that these proteins were enriched in the 'regulation of cytoskeleton actin', 'focal adhesion' and 'chemokine signaling pathways', suggesting that PEVs may participate in several pathophysiological processes (Fig. 1). Notably, three of the chemokines in PEVs (CCL5, CXCL4 and CXCL7) were involved in chemokine signaling pathways.

PEVs promotes reorganization of the actin cytoskeleton of RA-FLS. It has been reported that PEVs can promote the motility of RA-FLS. Considering that the dynamic reorganization of the actin cytoskeleton is critical for directional cell migration $(22,26)$, additional fluorescent phalloidin staining was performed in the present study to determine whether cytoskeletal changes are induced by PEVs. As shown in Fig. 2, treatment with PEVs increased the number of fibers in cells, and facilitated lamellipodia and filopodia formation at the leading edge of migrating cells, suggesting that PEVs indeed promote cell invasion and migration.

Effects of chemokine receptor antagonists on the migration and invasion of RA-FLS induced by PEVs. Considering that chemokines play important roles by binding to their respective receptors (CCL5 receptor CCR1, CXCL4 receptor CXCR3 and CXCL7 receptor CXCR2), the following corresponding chemokine receptor antagonists were investigated in the present study: BX471 (CCR1 antagonist), AMG487 (CXCR3 antagonist) and SB225002 (CXCR2 antagonist). First, the effects of the three antagonists on the viability of RA-FLS were investigated. As presented in Fig. 3, different concentrations of BX471 (50, 100 and $150 \mathrm{nM})$, AMG487 $(0.5,1$ and $2 \mu \mathrm{M})$ and SB225002 (0.1, 0.2 and $0.4 \mu \mathrm{M})$ exerted no significant effects 


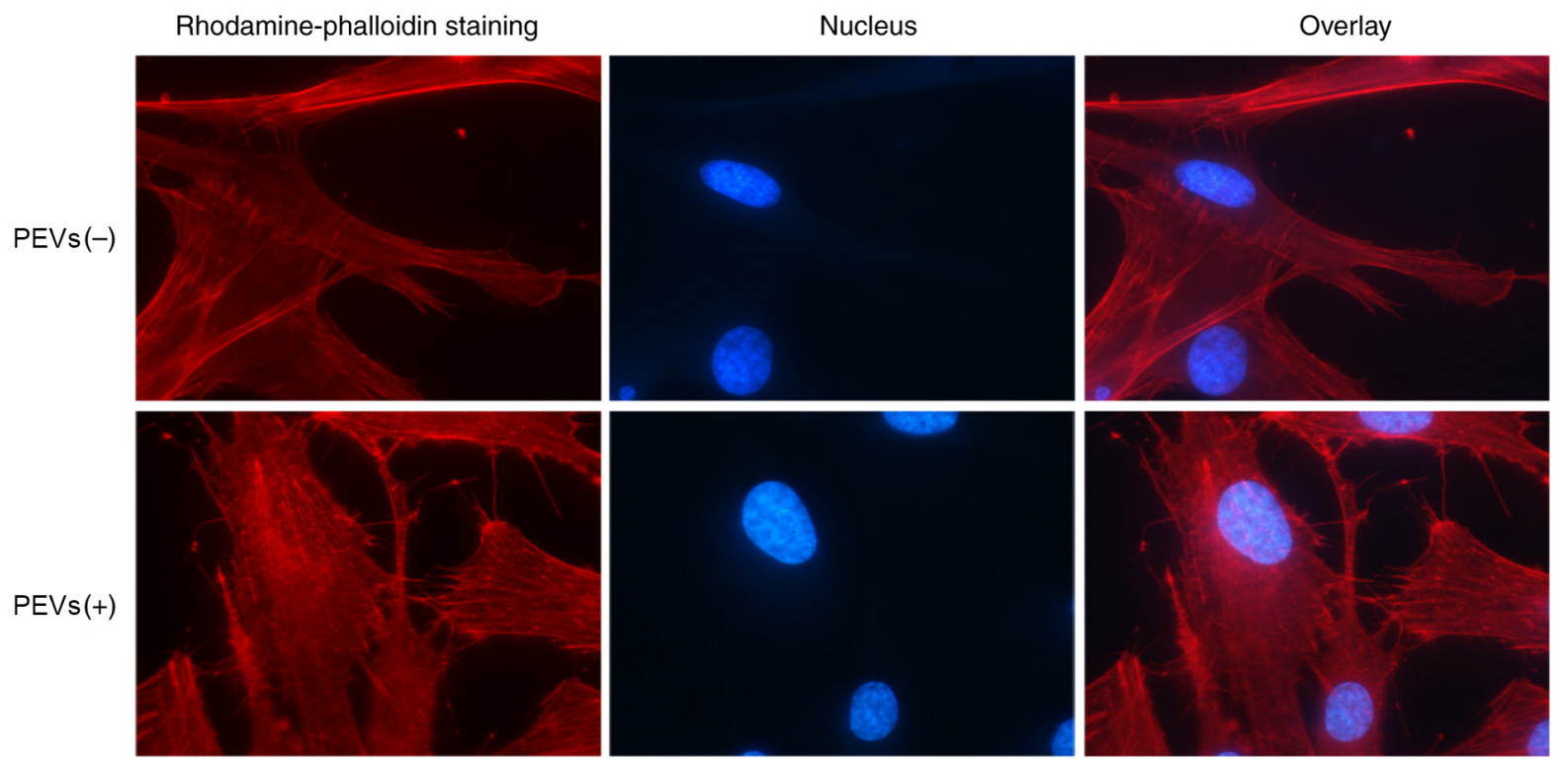

Figure 2. Modulation of actin cytoskeletal reorganization in RA-FLS induced by PEVs. RA-FLS were treated with or without PEVs for $24 \mathrm{~h}$. Cells were fixed and subjected to immunofluorescence staining with rhodamine-conjugated phalloidin (for F-actin, green color) and DAPI (for nucleus, blue color) staining. Original magnification, x100. RA-FLS, rheumatoid arthritis fibroblast-like synoviocytes; PEVs, platelet-derived extracellular vesicles.

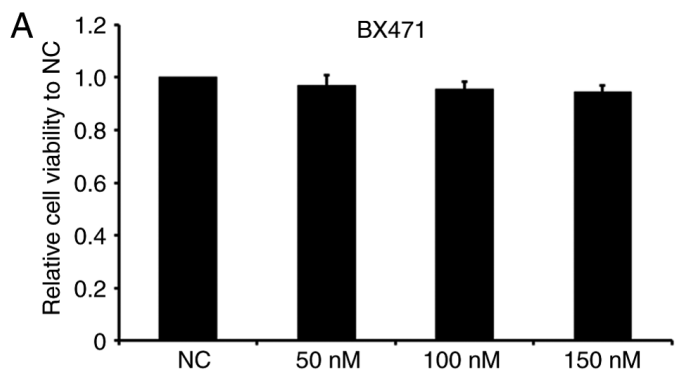

B

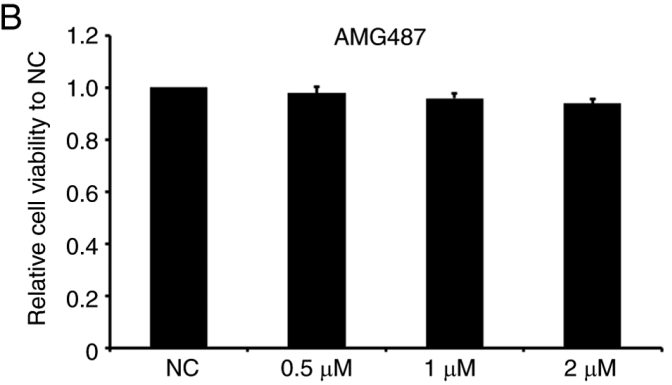

C

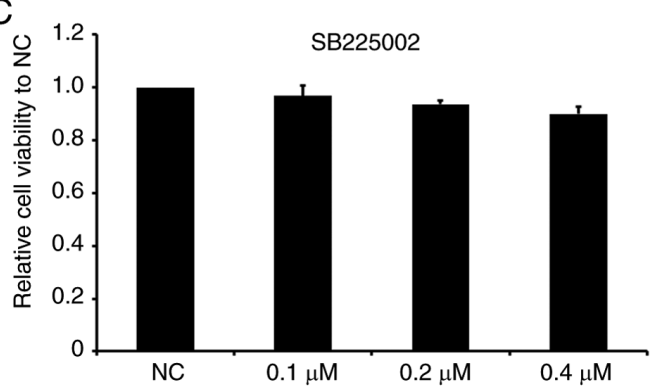

Figure 3. Effects of chemokine receptor antagonists on the viability of RA-FLS. RA-FLS were treated with different concentrations of three chemokine receptor antagonists or NC, and the Cell Counting Kit- 8 assay was performed to assess cell proliferation. (A) BX471 (CCR1 antagonist), (B) AMG487 (CXCR3 antagonist) and (C) SB225002 (CXCR2 antagonist). Percentage of cell viability was calculated relative to NC. Data are presented as the mean $\pm \mathrm{SD}(\mathrm{n}=3)$. RA-FLS, rheumatoid arthritis fibroblast-like synoviocytes; NC, negative control; CCR1, C-C motif chemokine ligand 5 receptor; CXCR, C-X-C motif chemokine receptor. on cell viability compared with the control group, suggesting that the chemokine receptor antagonists themselves did not affect the viability of RA-FLS within the range of detected concentrations.

The migration and invasion of RA-FLS are crucial characteristics that are associated with cartilage and bone erosion during RA $(5,6)$. To assess the effects of the three chemokine receptor antagonists on the invasive and migratory abilities of RA-FLS in the presence or absence of PEVs, wound healing assay, and Transwell migration and invasion assays were performed. As presented in Fig. 4, PEVs significantly promoted the migration of RA-FLS, which is consistent with previous findings (22). However, SB225002 was demonstrated to partially antagonize the migration of RA-FLS induced by PEVs, whereas no significant effects of BX471 or AMG487 on the migration of RA-FLS were observed, in the presence or absence of PEVs. The effect of SB225002 on the invasion of RA-FLS in the presence or absence of PEVs was also investigated. As expected, the results of the Transwell invasion assay demonstrated that SB225002 partially antagonized the invasion of RA-FLS induced by PEVs, suggesting that PEVs may affect the motility of RA-FLS via a CXCR2-mediated signaling pathway.

PEVs activated the CXCR2-mediated $N F-\kappa B$ pathway in $R A-F L S$. It has been reported that PEVs may promote the migration and invasion of RA-FLS by upregulating MMP-1 expression via activation of ERK/NF- $\kappa \mathrm{B}$ signaling (22). Considering that SB225002 partially inhibits migration and invasion of RA-FLS induced by PEVs, as mentioned above, it was next investigated whether PEVs activate $\mathrm{NF}-\kappa \mathrm{B}$ via the CXCR2-mediated signaling pathway. As presented in Fig. 5, SB225002 at different concentrations $(0.1,0.2$ and $0.4 \mu \mathrm{M})$ markedly decreased the phosphorylation of $\mathrm{I} \kappa \mathrm{B}$ and $\mathrm{NF}-\kappa \mathrm{B}$ in RA-FLS. Of note, this tendency was more significant following treatment with PEVs, suggesting that SB225002 can inhibit 
A a
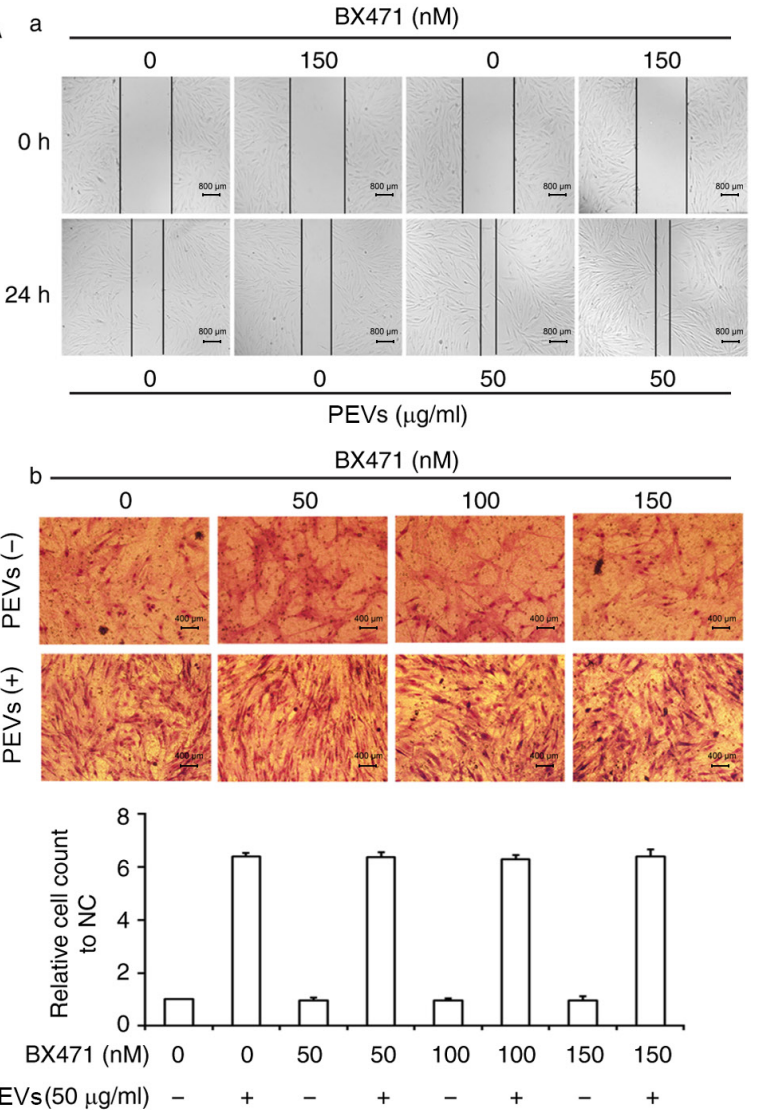

C a

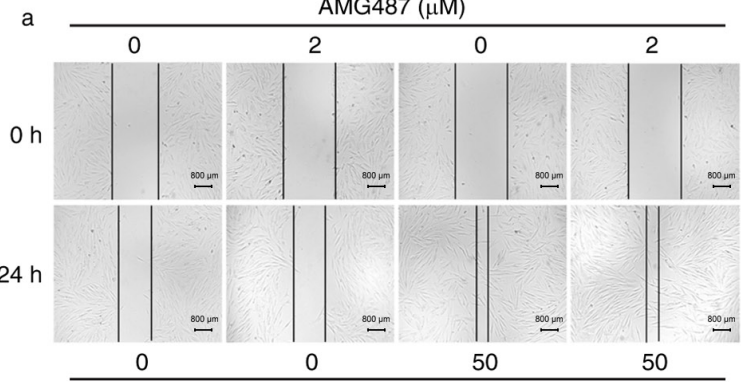

PEVs $(\mu \mathrm{g} / \mathrm{ml})$

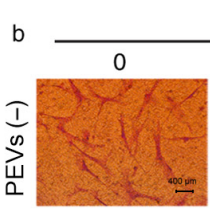

AMG487 $(\mu \mathrm{M})$
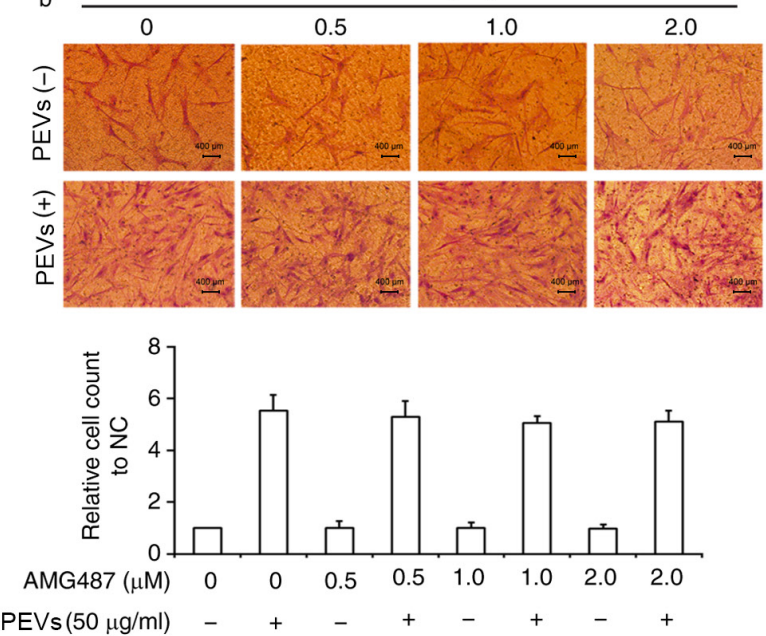

$\mathrm{B}$ a $\mathrm{SB} 225002(\mu \mathrm{M})$
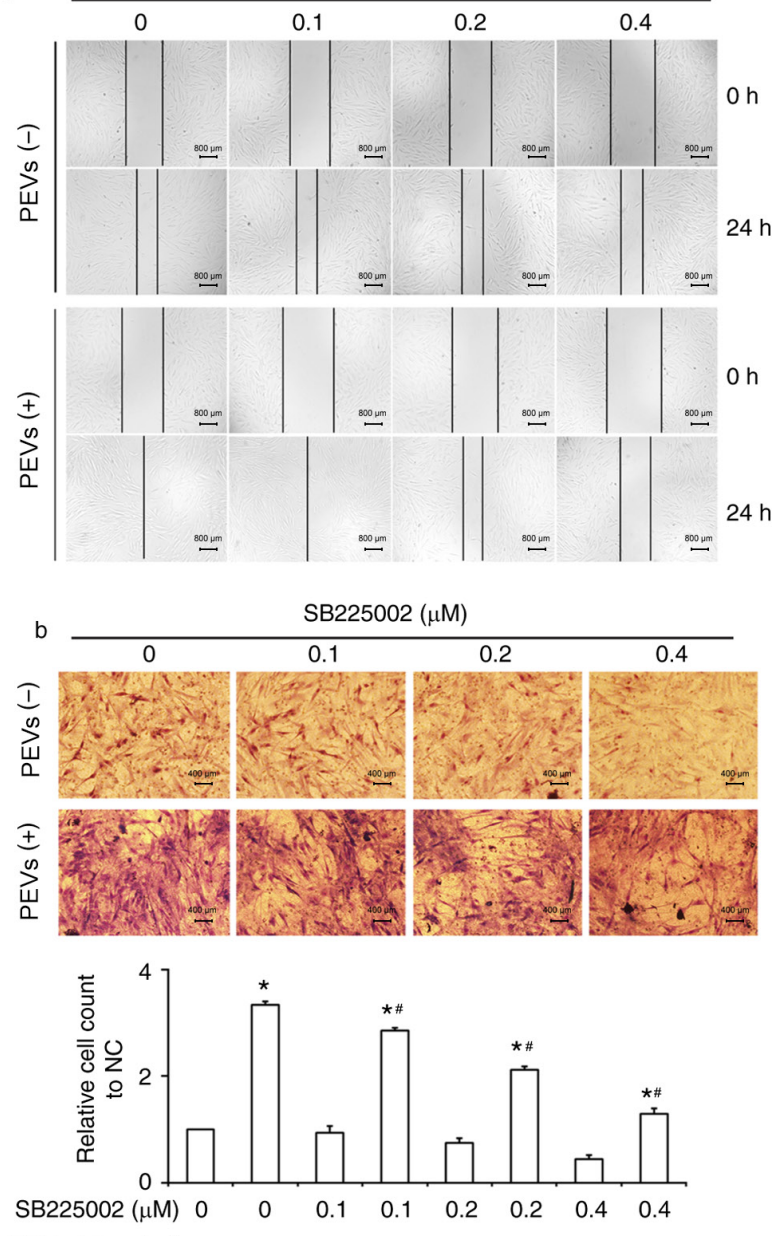

$\operatorname{PEVs}(50 \mu \mathrm{g} / \mathrm{ml})-+\ldots+\ldots+$
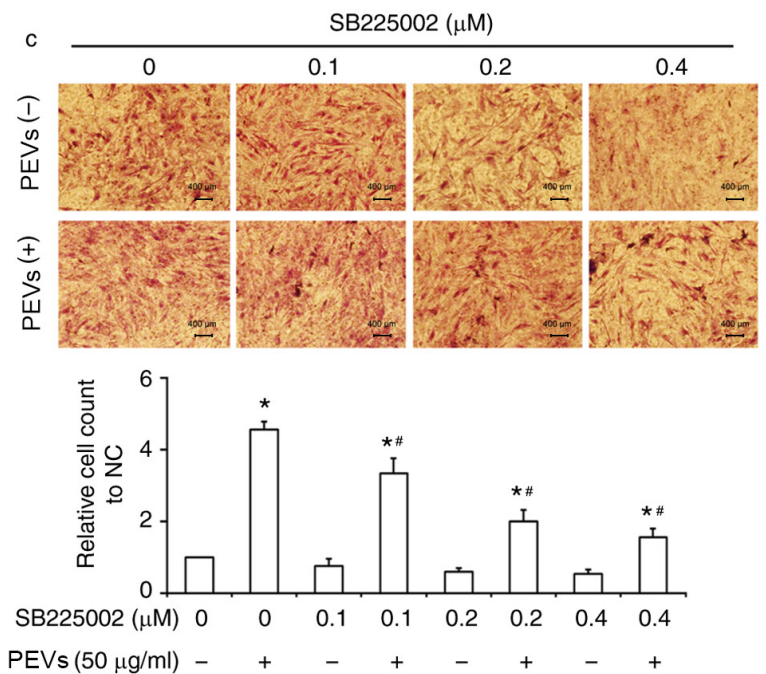

Figure 4. Effects of chemokine receptor antagonists on the migration and invasion of RA-FLS induced by PEVs. (A) Wound healing (a) and Transwell (b) assays were performed on RA-FLS treated with or without PEVs with different concentrations of BX471. (B) Wound healing (a), Transwell migration (b) and invasion assays (c) were performed on RA-FLS treated with or without PEVs with different concentrations of SB225002. (C) Wound healing (a) and (b) Transwell assays were performed on RA-FLS treated with or without PEVs with different concentrations of AMG487. Original magnification, x100. Wound healing scale bar, $800 \mu \mathrm{m}$; Transwell assay scale bar, $400 \mu \mathrm{m}$. Data are presented as the mean $\pm \mathrm{SD}(\mathrm{n}=3)$. ${ }^{*} \mathrm{P}<0.05$ vs. the control group; $\mathrm{P}<0.05 \mathrm{vs.} 50 \mu \mathrm{g} / \mathrm{ml}$ PEVs group. RA-FLS, rheumatoid arthritis fibroblast-like synoviocytes; PEVs, platelet-derived extracellular vesicles. 
A

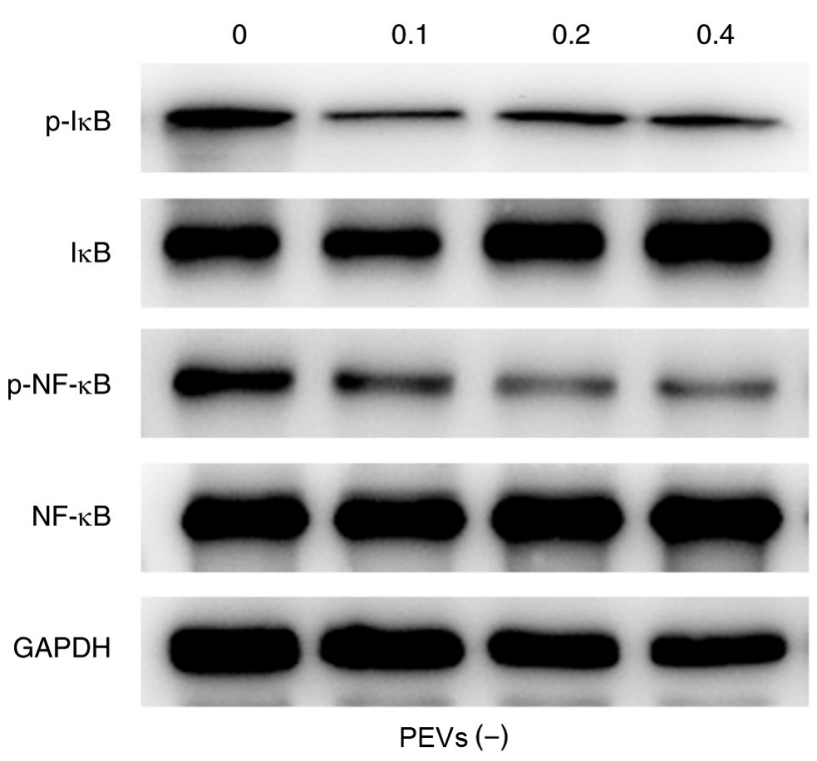

B
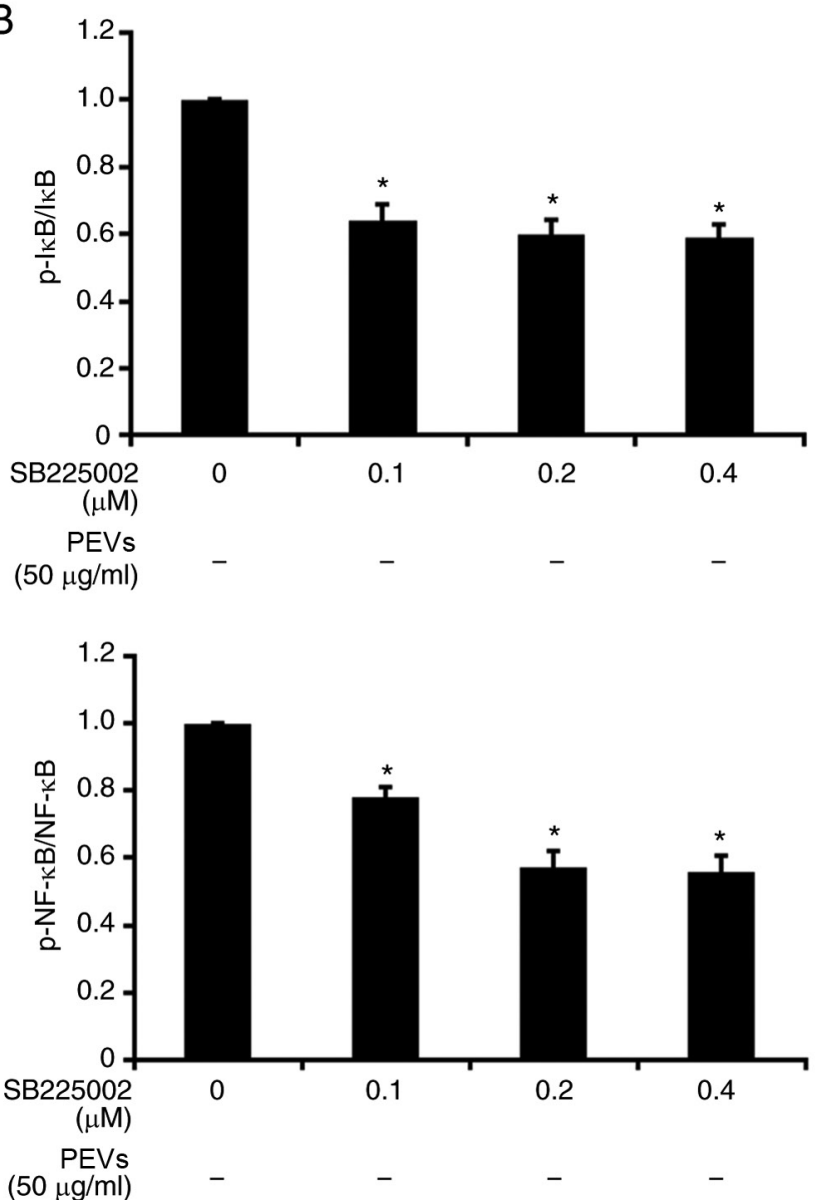
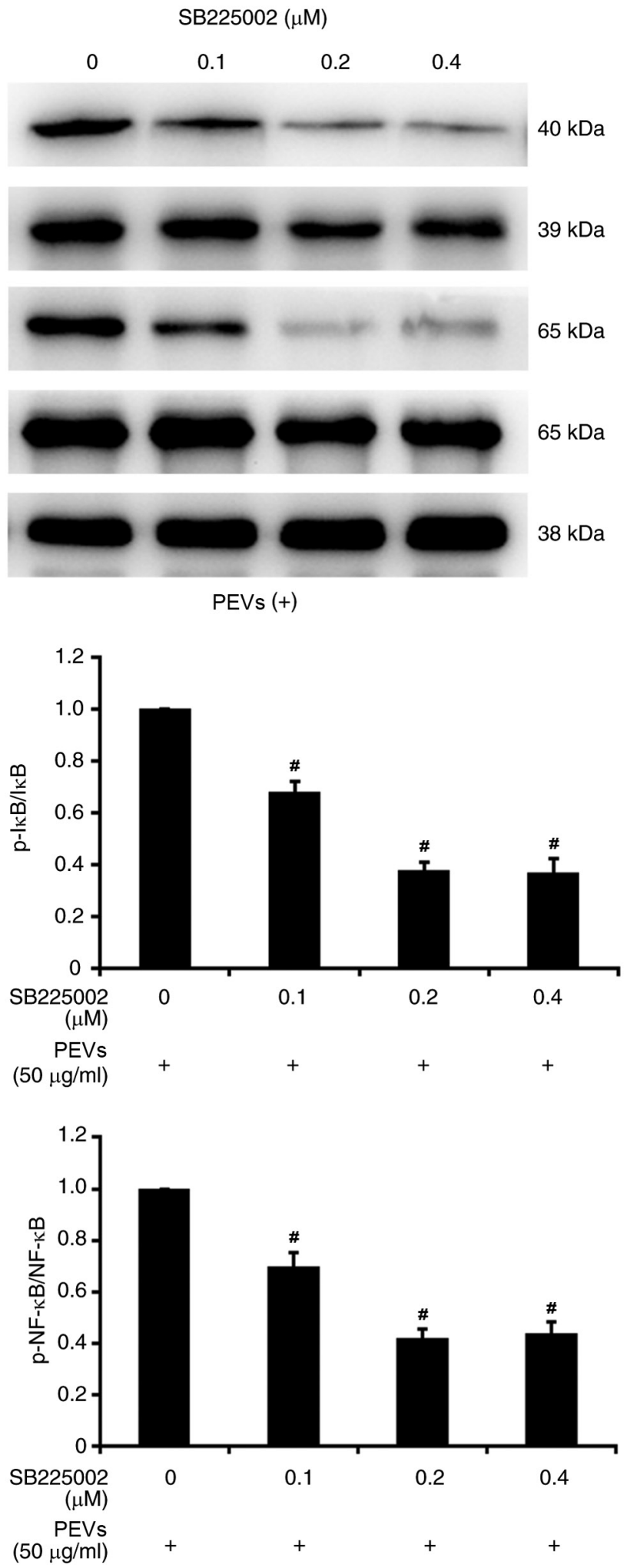

Figure 5. PEVs activate the CXCR2-mediated NF- $\kappa \mathrm{B}$ pathway in RA-FLS. (A) Western blotting was performed to detect the expression levels of I $\kappa$ B, p-I $\kappa \mathrm{B}$, NF- $\kappa$ B and p-NF- $\kappa$ B in RA-FLS following treatment with different concentrations of SB225002, with or without PEVs. Representative blots of three independent experiments are demonstrated and were normalized against GAPDH. (B) Semi-quantification of fold change in $\mathrm{p}-\mathrm{I} \kappa \mathrm{B}$ relative to total $\mathrm{I} \kappa \mathrm{B}$ and $\mathrm{p}-\mathrm{NF}-\kappa \mathrm{B}$ relative to total $\mathrm{NF}-\kappa \mathrm{B}$ are presented as the mean $\pm \mathrm{SD} .{ }^{*} \mathrm{P}<0.05$ vs. the control group; ${ }^{*} \mathrm{P}<0.05$ vs. $50 \mu \mathrm{g} / \mathrm{ml} \mathrm{PEVs}$ group. PEVs, platelet-derived extracellular vesicles; NF, nuclear factor; RA-FLS, rheumatoid arthritis fibroblast-like synoviocytes; p, phosphorylated; CXCR2, C-X-C motif chemokine receptor 2.

the activating effect of PEVs on NF- $\kappa B$ signaling in RA-FLS. Taken together, these results suggest that PEVs may regulate the migration and invasion of RA-FLS via CXCR2-mediated activation of the NF- $\mathrm{kB}$ pathway.

\section{Discussion}

RA-FLS, the dominant non-immune cells of synovial tissues in patients with RA, contribute to the development 
of synovitis, pannus formation and joint destruction via multiple mechanisms (3). Increasing evidence suggests that migration and invasion of RA-FLS play important roles in RA initiation and progression (4-6). As regards the promoting effect of PEVs on the motility of RA-FLS, the present study demonstrated that PEVs regulate the actin cytoskeletal reorganization in RA-FLS, which further verified the active role of PEVs in cell motility, consistent with previous findings (22). To identify the main active contents and determine the molecular mechanism through which PEVs regulate the motility of RA-FLS, LC-MS-MS analysis was performed to identify the proteins of PEVs, which included several significant chemokines, such as CCL5, CXCL4 and CXCL7. Previous studies have demonstrated that these three chemokines are involved in chemokine signaling pathways that are closely associated with cell migration and invasion (27-29). According to GO analysis, the biological processes these chemokines participate in principally include 'signal transduction', 'transport', 'establishment of localization', 'regulation of developmental process' and 'negative regulation of biological process'; the molecular functions include 'substrate-specific transporter activation' and 'receptor binding'. KEGG annotation revealed that these chemokines are mainly involved in the 'chemokine signaling pathway'.

Considering that chemokines play important roles in autoimmune diseases, tumor-related inflammation and immunity, as well as tumor growth and metastasis, it was hypothesized that the chemokines in PEVs can affect the motility of RA-FLS (30-32). In RA, CCL5 and its receptor, CCR1, are abundantly expressed in synovial tissue and involved in monocyte and $\mathrm{T}$ lymphocyte recruitment to the joints (33). CXCL4/CXCR3 may be involved in lymphocyte chemotaxis to target organs in patients with systemic lupus erythematosus, and have been reported to be associated with disease activity (34). Notably, higher levels of synovial CXCL4 and CXCL7 have been detected in early RA compared with resolving arthritis or established RA (35). Taken together, these results suggest that the chemokine/chemokine receptor axis may be a suitable target for disease treatment. Chemokines and their receptors have been implicated in inflammatory cell recruitment and angiogenesis, which underlie the pathogenesis of RA (36). To verify whether PEVs modulate the motility of RA-FLS via the chemokine/chemokine receptor pathway, BX471 (CCR1 antagonist), AMG487 (CXCR3 antagonist) and SB225002 (CXCR2 antagonist) were selected in the present study. None of these antagonists exerted significant effects on the viability of RA-FLS. The results from the wound healing and Transwell assays demonstrated that BX471 and AMG487 were unable to block the migration of RA-FLS induced by PEVs. Conversely, SB225002 partially antagonized the migration and invasion of RA-FLS induced by PEVs, suggesting that PEVs may promote the migration and invasion of RA-FLS via a CXCR2-mediated signaling pathway.

$\mathrm{NF}-\kappa \mathrm{B}$ is activated by several agents, including cytokines, oxidant free radicals, bacterial or viral products and ultraviolet irradiation (37). Since PEVs presumably play a promoting role in the regulation of motility of RA-FLS by activating $\mathrm{NF}-\kappa \mathrm{B}$ signaling, the present study investigated whether the activation of $\mathrm{NF}-\kappa \mathrm{B}$ signaling was mediated by CXCR2. As expected, the results confirmed that SB225002 decreased the phosphorylation of I $\mathrm{B}$ and NF- $\kappa \mathrm{B}$ in RA-FLS induced by PEVs, rather than affecting CXCR2 expression. When the CXCL7/CXCR2 axis in RA-FLS is stimulated, the extracellular signal is transmitted to the cytoplasm, which triggers the phosphorylation of $\mathrm{I}-\kappa \mathrm{B}$, which is degraded by the proteasome. Subsequently, $\mathrm{NF}-\kappa \mathrm{B}$ is released and transferred into the nucleus, initiating transcription of related genes, including inflammatory cytokines, chemokines and MMPs, resulting in the malignant transformation and metastasis of cells $(38,39)$.

In conclusion, understanding the role of the main active contents of PEVs in the occurrence and development of RA may be crucial for exploring therapeutic targets. The findings of the present study demonstrated that the CXCR2 antagonist exerted an antagonistic effect against PEVs by decreasing $\mathrm{I} \kappa \mathrm{B}$ and $\mathrm{NF}-\kappa \mathrm{B}$ phosphorylation in RA-FLS, indicating that CXCL7/CXCR2 may be a potential therapeutic target for RA. However, further studies on specific downstream factors of this signaling pathway and verification in animal models are required to further elucidate the role of PEVs in RA and develop novel therapeutic strategies.

\section{Acknowledgements}

Not applicable.

\section{Funding}

The present study was supported by the National Natural Science Foundation of China (grant no. 81470070) and Nantong Science and Technology Bureau (grant no. JC2020037).

\section{Availability of data and materials}

The datasets used and/or analyzed during the current study are available from the corresponding author on reasonable request.

\section{Authors' contributions}

YZ and WS were responsible for the concept and design of the study. WW, ZD, GL and JY performed experiments and data analysis. WW, WZ and CZ performed data interpretation, presentation and writing of the manuscript. WW and $\mathrm{YZ}$ confirm the authenticity of all the raw data. All authors have read and approved the final manuscript.

\section{Ethics approval and consent to participate}

Not applicable.

\section{Patient consent for publication}

Not applicable.

\section{Competing interests}

The authors declare that they have no competing interests. 


\section{References}

1. Smolen JS, Aletaha D, Barton A, Burmester GR, Emery P, Firestein GS, Kavanaugh A, McInnes IB, Solomon DH, Strand V and Yamamoto K: Rheumatoid arthritis. Nat Rev Dis Primers 4: 18001, 2018.

2. Román-Fernández IV, García-Chagollán M, Cerpa-Cruz S, Jave-Suárez LF, Palafox-Sánchez CA, García-Arellano S, Sánchez-Zuno GA and Muñoz-Valle JF: Assessment of CD40 and CD40L expression in rheumatoid arthritis patients, association with clinical features and DAS28. Clin Exp Med 19: 427-437, 2019.

3. Bartok B and Firestein GS: Fibroblast-like synoviocytes: Key effector cells in rheumatoid arthritis. Immunol Rev 233: 233-255, 2010.

4. Kawaguchi Y, Waguri-Nagaya Y, Tatematsu N, Oguri Y, Kobayashi M, Nozaki M, Asai K, Aoyama M and Otsuka T: The Janus kinase inhibitor tofacitinib inhibits TNF- $\alpha$-induced gliostatin expression in rheumatoid fibroblast-like synoviocytes. Clin Exp Rheumatol 36: 559-567, 2018.

5. Schönfeld C, Pap T, Neumann E and Müller-Ladner U: Fibroblasts as pathogenic cells in rheumatic inflammation. Z Rheumatol 74: 33-38, 2015 (In German).

6. Müller-Ladner U, Pap T, Gay RE, Neidhart M and Gay S: Mechanisms of disease: The molecular and cellular basis of joint destruction in rheumatoid arthritis. Nat Clin Pract Rheumatol 1: 102-110, 2005.

7. Ponomareva AA, Nevzorova TA, Mordakhanova ER, Andrianova IA, Rauova L, Litvinov RI and Weisel JW: Intracellular origin and ultrastructure of platelet-derived microparticles. J Thromb Haemost 15: 1655-1667, 2017.

8. Rosińska J, Łukasik M and Kozubski W: The impact of vascular disease treatment on Platelet-Derived Microvesicles. Cardiovasc Drugs Ther 31: 627-644, 2017.

9. Vismara $\mathrm{M}$, Zarà $\mathrm{M}$, Negri $\mathrm{S}$, Canino J, Canobbio I, Barbieri SS, Moccia F, Torti M and Guidetti GF: Platelet-derived extracellular vesicles regulate cell cycle progression and cell migration in breast cancer cells. Biochim Biophys Acta Mol Cell Res 1868: 118886, 2021.

10. Vajen T, Mause SF and Koenen RR: Microvesicles from platelets: Novel drivers of vascular inflammation. Thromb Haemost 114: 228-236, 2015.

11. Sellam J, Proulle V, Jüngel A, Ittah M, Miceli Richard C, Gottenberg JE, Toti F, Benessiano J, Gay S, Freyssinet JM and Mariette X: Increased levels of circulating microparticles in primary Sjögren's syndrome, systemic lupus erythematosus and rheumatoid arthritis and relation with disease activity. Arthritis Res Ther 11: R156, 2009.

12. Olumuyiwa-Akeredolu OO, Page MJ, Soma P and Pretorius E: Platelets: Emerging facilitators of cellular crosstalk in rheumatoid arthritis. Nat Rev Rheumatol 15: 237-248, 2019.

13. Chaturvedi S, Cockrell E, Espinola R, His L, Fulton S, Khan M, Li L, Fonseca F, Kundu S and McCrae KR: Circulating microparticles in patients with antiphospholipid antibodies: Characterization and associations. Thromb Res 135: 102-108, 2015.

14. Knijff-Dutmer EA, Koerts J, Nieuwland R, Kalsbeek-Batenburg EM and van de Laar MA: Elevated levels of platelet microparticles are associated with disease activity in rheumatoid arthritis. Arthritis Rheum 46: 1498-1503, 2002.

15. Boilard E, Nigrovic PA, Larabee K, Watts GF, Coblyn JS, Weinblatt ME, Massarotti EM, Remold-O'Donnell E, Farndale RW, Ware J and Lee DM: Platelets amplify inflammation in arthritis via collagen-dependent microparticle production. Science 327: 580-583, 2010.

16. Puddu P, Puddu GM, Cravero E, Muscari S and Muscari A: The involvement of circulating microparticles in inflammation, coagulation and cardiovascular diseases. Can J Cardiol 26 : 140-145, 2010

17. Italiano JE Jr, Mairuhu AT and Flaumenhaft R: Clinical relevance of microparticles from platelets and megakaryocytes. Curr Opin Hematol 17: 578-584, 2010.

18. Villar-Vesga J, Grajales C, Burbano C, Vanegas-García A, Muñoz-Vahos CH, Vásquez G, Rojas M and Castaño D: Platelet-derived microparticles generated in vitro resemble circulating vesicles of patients with rheumatoid arthritis and activate monocytes. Cell Immunol 336: 1-11, 2019.

19. Dashevsky O, Varon D and Brill A: Platelet-derived microparticles promote invasiveness of prostate cancer cells via upregulation of MMP-2 production. Int J Cancer 124: 1773-1777, 2009.
20. Janowska-Wieczorek A, Wysoczynski M, Kijowski J, Marquez-Curtis L, Machalinski B, Ratajczak J and Ratajczak MZ: Microvesicles derived from activated platelets induce metastasis and angiogenesis in lung cancer. Int J Cancer 113: 752-760, 2005.

21. Barteneva NS, Fasler-Kan E, Bernimoulin M, Stern JN, Ponomarev ED, Duckett L and Vorobjev IA: Circulating microparticles: Square the circle. BMC Cell Biol 14: 23, 2013.

22. Wang W, Liu J, Yang B, Ma Z, Liu G, Shen W and Zhang Y: Modulation of platelet-derived microparticles to adhesion and motility of human rheumatoid arthritis fibroblast-like synoviocytes. PLoS One 12: e0181003, 2017.

23. Grépin R, Guyot M, Giuliano S, Boncompagni M, Ambrosetti D, Chamorey E, Scoazec JY, Negrier S, Simonnet H and Pagès G: The CXCL7/CXCR1/2 axis is a key driver in the growth of clear cell renal cell carcinoma. Cancer Res 74: 873-883, 2014.

24. Markov DA, Savkina M, Anikin M, Del Campo M, Ecker K, Lambowitz AM, De Gnore JP and McAllister WT: Identification of proteins associated with the yeast mitochondrial RNA polymerase by tandem affinity purification. Yeast 26: 423-440, 2009.

25. Nadar M, Chan MY, Huang SW, Huang CC, Tseng JT and Tsai CH: HuR binding to AU-rich elements present in the 3' untranslated region of Classical swine fever virus. Virol J 8: 340, 2011.

26. Sun BO, Fang Y, Li Z, Chen Z and Xiang J: Role of cellular cytoskeleton in epithelial-mesenchymal transition process during cancer progression. Biomed Rep 3: 603-610, 2015.

27. An G, Wu F, Huang S, Feng L, Bai J, Gu S and Zhao X: Effects of CCL5 on the biological behavior of breast cancer and the mechanisms of its interaction with tumor-associated macrophages. Oncol Rep 42: 2499-2511, 2019.

28. Quemener C, Baud J, Boyé K, Dubrac A, Billottet C, Soulet F, Darlot F, Dumartin L, Sire M, Grepin R, et al: Dual roles for CXCL4 chemokines and CXCR3 in angiogenesis and invasion of pancreatic cancer. Cancer Res 76: 6507-6519, 2016.

29. Guo Q, Jian Z, Jia B and Chang L: CXCL7 promotes proliferation and invasion of cholangiocarcinoma cells. Oncol Rep 37: 1114-1122, 2017.

30. Szekanecz Z and Koch AE: Successes and failures of chemokine-pathway targeting in rheumatoid arthritis. Nat Rev Rheumatol 12: 5-13, 2016.

31. MiyabeY, Lian J, Miyabe C and Luster AD: Chemokines in rheumatic diseases: Pathogenic role and therapeutic implications. Nat Rev Rheumatol 15: 731-746, 2019.

32. Karin $\mathrm{N}$ and Razon $\mathrm{H}$ : Chemokines beyond chemo-attraction: CXCL10 and its significant role in cancer and autoimmunity. Cytokine 109: 24-28, 2018.

33. Haringman JJ, Smeets TJ, Reinders-Blankert P and Tak PP: Chemokine and chemokine receptor expression in paired peripheral blood mononuclear cells and synovial tissue of patients with rheumatoid arthritis, osteoarthritis, and reactive arthritis. Ann Rheum Dis 65: 294-300, 2006

34. Im CH, Park JA, Kim JY, Lee EY, Lee EB, Kim Y and Song YW: CXCR3 polymorphism is associated with male gender and pleuritis in patients with systemic lupus erythematosus. Hum Immunol 75: 466-469, 2014.

35. Yeo L, Adlard N, Biehl M, Juarez M, Smallie T, Snow M, Buckley CD, Raza K, Filer A and Scheel-Toellner D: Expression of chemokines CXCL4 and CXCL7 by synovial macrophages defines an early stage of rheumatoid arthritis. Ann Rheum Dis 75: 763-771, 2016.

36. Szekanecz Z, Koch AE and Tak PP: Chemokine and chemokine receptor blockade in arthritis, a prototype of immune-mediated inflammatory diseases. Neth J Med 69: 356-366, 2011.

37. DiDonato JA, Mercurio F and Karin M: NF- $\mathrm{BB}$ and the link between inflammation and cancer. Immunol Rev 246: 379-400, 2012.

38. Dong YL, Kabir SM, Lee ES and Son DS: CXCR2-driven ovarian cancer progression involves upregulation of proinflammatory chemokines by potentiating NF- $\mathrm{KB}$ activation via EGFR-transactivated Akt signaling. PLoS One 8: e83789, 2013.

39. Zhang Z, Tan X, Luo J, Cui B, Lei S, Si Z, Shen L and Yao H: GNA13 promotes tumor growth and angiogenesis by upregulating $\mathrm{CXC}$ chemokines via the NF- $\kappa \mathrm{B}$ signaling pathway in colorectal cancer cells. Cancer Med 7: 5611-5620, 2018.

This work is licensed under a Creative Commons Attribution-NonCommercial-NoDerivatives 4.0 International (CC BY-NC-ND 4.0) License. 